in vivo $34: 2933-2939(2020)$

doi:10.21873/invivo.12123

\title{
Laparoscopic Total Gastrectomy for Gastric Cancer in Elderly Patients
}

\author{
HIDEAKI SUEMATSU ${ }^{1}$, CHIKARA KUNISAKI ${ }^{1}$, HIROSHI MIYAMATO ${ }^{1}$, KEI SATO ${ }^{1}$, SHO SATO ${ }^{1}$, \\ YUSAKU TANAKA ${ }^{1}$, NORIO YUKAWA ${ }^{2}$, YASUSHI RINO ${ }^{2}$, TAKASHI KOSAKA $^{3}$, \\ HIROTOSHI AKIYAMA ${ }^{3}$, ITARU ENDO ${ }^{3}$ and MUNETAKA MASUDA ${ }^{2}$ \\ ${ }^{1}$ Department of Surgery, Gastroenterological Center, Yokohama City University, Yokohama, Japan; \\ ${ }^{2}$ Department of Surgery, Yokohama City University, Graduate School of Medicine, Yokohama, Japan; \\ ${ }^{3}$ Department of Gastroenterological Surgery, Yokohama City University, \\ Graduate School of Medicine, Yokohama, Japan
}

\begin{abstract}
Background/Aim: The purpose of this study was to evaluate the safety and efficacy of laparoscopic total gastrectomy (LTG) for elderly patients. Patients and Methods: We retrospectively analyzed 136 patients who underwent LTG. We divided the patients into elderly patients (>75 years of age) and non-elderly patients ( $\leq 75$ years of age). Results: The American Society of Anesthesiologists score, Charlson comorbidity index, Glasgow Prognostic Score and rate of comorbidities were higher in the elderly group; the rates of other clinicopathological characteristics did not differ between the two groups. Regarding the nutritional status, the body weight loss rate in the elderly group was higher in comparison to the non-elderly group ( $81 \%$ vs. $84 \%, p=0.004)$. The disease-specific survival (DSS) did not differ between two groups to a statistically significant extent (3-year DSS rates: 83.7 vs. 94.5\%; $p=0.152$ ). Conclusions: LTG was acceptable for elderly patients as the elderly and non-elderly groups showed comparable shortterm and long-term outcomes.
\end{abstract}

In recent years, the aging of the global population is progressing, and the prolongation of life expectancy in Japan has been remarkable. Elderly people ( $\geq 65$ years of age) account for more than $25 \%$ of the Japanese population, and

This article is freely accessible online.

Correspondence to: Chikara Kunisaki, MD, Ph.D., Department of Surgery, Gastroenterological Center, Yokohama City University, 457 Urafune-cho, Minami-ku, Yokohama, 232-0024, Japan. Tel: +81 452615656, Fax: +81 452619492, e-mail: s0714@med.yokohamacu.ac.jp

Key Words: Laparoscopic total gastrectomy, gastric cancer, elderly patients, nutritional state. are expected to account for $40 \%$ of the population in 2060 (1). Thus, the number of elderly gastric cancer patients is expected to increase, and it is necessary to evaluate appropriate therapeutic strategies for elderly patients. Generally, these patients have various comorbidities including cardiovascular and respiratory diseases (2-6), thus, minimally invasive treatment is mandatory.

Since it was reported by Kitano et al. (7), laparoscopic distal gastrectomy (LDG) has been widely performed in Japan and East Asian countries in recent years as a minimally invasive operation for gastric cancer. Laparoscopic total gastrectomy (LTG) is also being performed for gastric cancer that is mainly located in the upper third of the stomach (8-10). However, LTG has not been regarded as a standard procedure for early gastric cancer due to its technical difficulties and the complexity of reconstruction; thus, this is not listed in the Japanese Gastric Cancer Treatments Guidelines (11). Recently, several studies on LTG in gastric cancer patients have reported favorable short-term and long-term outcomes in comparison to open surgery (12-14). However, the surgical safety and efficacy and oncological usefulness of LTG for elderly patients is still unclear. Thus, this study aimed to clarify the safety and efficacy of LTG for elderly patients with gastric cancer.

\section{Patients and Methods}

Patients. We retrospectively analyzed 136 patients with gastric cancer that was mainly located in the upper third of the stomach, who underwent no residual tumor (R0) resection LTG with regional lymph node dissection at the Department of Surgery, Gastroenterological Center and the Department of Gastroenterological Surgery, Yokohama City University, Japan, between January 2013 and December 2018. Preoperative clinical staging was based on upper gastrointestinal endoscopy, upper gastrointestinal series and enhanced computed tomography. The clinicopathological findings of the patients were based on the Japanese Classification of Gastric 
Carcinoma (3rd English edition) (11). Patients with pathologically confirmed gastric adenocarcinoma and without neoadjuvant chemotherapy were included in this study. Initially, LTG was introduced for clinical stage I gastric cancer patients in our institutions. The indication of LTG was gradually extended to clinical stage II gastric cancer patients, in accordance with the operator's proficiency. Patients, who required conversion to open surgery due to the detection of tumor serosal invasion (T4a) in the initial laparoscopic observation were excluded from this study.

Patients were divided into two groups according to age: elderly patients ( $>75$ years of age) and non-elderly patients ( $\leq 75$ years of age). The patients' data were collected by reviewing their medical records. The following parameters were evaluated: age, sex, body mass index (BMI), American Society of Anesthesiologists (ASA) score, comorbidities, Charlson comorbidity index (CCI), Glasgow Prognostic Score and clinical stage. The intraoperative outcomes (operative time and volume of blood loss) and postoperative clinical course (morbidities and length of hospital stay) were evaluated. Postoperative complications were defined according to the ClavienDindo classification system (Grade $\geq 2$ ). The long-term outcomes (overall and disease-free survival rates) were compared between the two groups. The change of body weight, hematological data (the serum level of albumin and hemoglobin), and prognostic nutritional index $(\mathrm{PNI})[10 \times$ serum albumin $(\mathrm{g} / \mathrm{dl})+0.005 \times$ peripheral lymph cell count $\left.\left(/ \mathrm{mm}^{3}\right)\right](15)$ were measured before surgery and at 6 and 12 months after gastrectomy.

Surgical procedure. An expert surgeon with experience of more than 100 laparoscopic gastrectomy cases performed the operation as the operator or assistant surgeon. The patient was placed in the supine position under general anesthesia; the surgeon mainly stood on the right side of the patient, the assistant surgeon on the left side of the patient, and the surgeon manipulating the endoscope stood between the patient's legs. A total of 37 patients underwent conventional LTG with five ports. Five trocars were introduced into the umbilicus (12 $\mathrm{mm}$; camera port), right upper quadrant $(5 \mathrm{~mm})$, right middle quadrant $(12 \mathrm{~mm})$, left upper quadrant $(12 \mathrm{~mm})$ and right middle quadrant $(12 \mathrm{~mm})$. The remaining 99 patients underwent reduced-port LTG with two ports. An OCTO ${ }^{\text {тм }}$ Port V2 (DalimSurgNet, Seoul, Korea) was inserted through an umbilical incision $(40 \mathrm{~mm})$ by the open technique, and a trocar was introduced into the right upper quadrant (12 mm) (9). Pneumoperitoneum was maintained at 12 $\mathrm{mmHg}$ during surgery.

For early gastric cancer, total gastrectomy with regional LN dissection using D1+ dissection, as defined by the Japanese classification of gastric carcinoma, was mainly performed (11). D2 dissection preserving the spleen was performed for patients with advanced gastric cancer. All patients underwent Roux-en-Y reconstruction, and the esophagojejunostomy was made intracorporeally using a circular stapling device. After hand-sewing a purse string suture at the abdominal esophageal stump, an anvil head was inserted. A jejunal loop was brought up behind the colon and through the transverse mesocolon intracorporeally. A DST Series ${ }^{\mathrm{TM}}$ EEA $^{\text {TM }}$ shaft was inserted into the jejunal loop extracorporeally, and esophagojejunostomy was performed. The jejunal stump was sutured intracorporeally using an Endo GIA ${ }^{\mathrm{TM}}$ universal stapler (60-2.5; Covidien). To create a 40-mm Roux-en-Y limb, the transected jejunum was used extracorporeally to form a side-to-side jejunojejunostomy using a DST Series ${ }^{\mathrm{TM}}$ EEA $^{\mathrm{TM}}$ stapler (25-3.5; Covidien).
Table I. Patient characteristics. The range is expressed as median (interquartile range).

\begin{tabular}{|c|c|c|c|}
\hline & $\begin{array}{l}\text { Elderly group } \\
\qquad(\mathrm{n}=34)\end{array}$ & $\begin{array}{l}\text { Non-elderly group } \\
\qquad(\mathrm{n}=102)\end{array}$ & $p$-Value \\
\hline Age (years) & $78.5(76-81)$ & $67(62-72)$ & $<0.001$ \\
\hline \multicolumn{4}{|l|}{ Gender } \\
\hline Male & $25(74 \%)$ & $74(73 \%)$ & 0.911 \\
\hline Female & $9(26 \%)$ & $28(27 \%)$ & \\
\hline BMI $\left(\mathrm{kg} / \mathrm{m}^{2}\right)$ & $23.9(22.0-25.5)$ & $23.2(20.8-25.6)$ & 0.751 \\
\hline ASA score & & & 0.033 \\
\hline 1 & $3(9 \%)$ & $29(28 \%)$ & \\
\hline 2 & $24(71 \%)$ & $63(62 \%)$ & \\
\hline 3 & $7(20 \%)$ & $10(10 \%)$ & \\
\hline $\begin{array}{l}\text { Past history of } \\
\text { laparotomy }\end{array}$ & $14(41 \%)$ & $23(23 \%)$ & 0.034 \\
\hline Cholecystectomy & $2(6 \%)$ & $3(3 \%)$ & 0.43 \\
\hline Appendectomy & $9(26 \%)$ & $16(16 \%)$ & 0.16 \\
\hline Portal gastrectomy & $1(3 \%)$ & 0 & 0.082 \\
\hline Colectomy & $1(3 \%)$ & $3(3 \%)$ & 1 \\
\hline Gynecological & $1(3 \%)$ & $4(4 \%)$ & 0.793 \\
\hline CCI & & & 0.011 \\
\hline 0 & $16(47 \%)$ & $67(66 \%)$ & \\
\hline 1 & $6(18 \%)$ & $22(22 \%)$ & \\
\hline 2 & $8(24 \%)$ & $11(11 \%)$ & \\
\hline 3 & $4(12 \%)$ & $1(1 \%)$ & \\
\hline 5 & 0 & $1(1 \%)$ & \\
\hline Comorbid disease & $32(94 \%)$ & $70(69 \%)$ & 0.003 \\
\hline Cardiovascular & $9(26 \%)$ & $15(15 \%)$ & 0.119 \\
\hline Hypertension & $24(71 \%)$ & $39(38 \%)$ & 0.001 \\
\hline Hyperlipidemia & $9(26 \%)$ & $19(19 \%)$ & 0.327 \\
\hline Diabetes melitus & $6(17 \%)$ & $14(14 \%)$ & 0.576 \\
\hline Respiratory & $3(9 \%)$ & $11(11 \%)$ & 0.745 \\
\hline Cerebrovascular & $2(6 \%)$ & $4(4 \%)$ & 0.63 \\
\hline Other cancer & $7(21 \%)$ & $7(7 \%)$ & 0.023 \\
\hline Other & $4(14 \%)$ & $14(14 \%)$ & 0.77 \\
\hline Albumin (g/dl) & $4.3(4.0-4.5)$ & $4.4(4.2-4.6)$ & 0.522 \\
\hline Hemoglobin (g/dl) & $13.1(12.1-14.0)$ & $13.5(12.3-14.8)$ & 0.263 \\
\hline $\begin{array}{l}\text { Prognostic } \\
\text { nutritional index }\end{array}$ & $51.4(48.3-56.0)$ & $52.6(49.6-55.9)$ & 0.833 \\
\hline Glasgow Prognostic & & & 0.041 \\
\hline \multicolumn{4}{|l|}{ Score } \\
\hline 0 & $30(88 \%)$ & $98(96 \%)$ & \\
\hline 1 & $2(6 \%)$ & $4(4 \%)$ & \\
\hline 2 & $2(6 \%)$ & 0 & \\
\hline$\% \mathrm{VC}(\%)$ & $99.0(87.5-107.8)$ & $102.7(94.8-111.8)$ & 0.193 \\
\hline \%FEV1.0 (\%) & $71.3(65.2--75.8)$ & $73.6(67.5-77.6)$ & 0.1 \\
\hline \multicolumn{4}{|l|}{ cT factor } \\
\hline $\mathrm{T} 1$ & $24(71 \%)$ & $74(73 \%)$ & 0.888 \\
\hline $\mathrm{T} 2$ & $8(23 \%)$ & $24(23 \%)$ & \\
\hline $\mathrm{T} 3$ & $2(6 \%)$ & $4(4 \%)$ & \\
\hline \multicolumn{4}{|l|}{$\mathrm{cN}$ factor } \\
\hline No & $22(65 \%)$ & $71(70 \%)$ & 0.744 \\
\hline N1 & $11(32 \%)$ & $25(24 \%)$ & \\
\hline $\mathrm{N} 2$ & $1(3 \%)$ & $5(5 \%)$ & \\
\hline N3 & 0 & $1(1 \%)$ & \\
\hline \multicolumn{4}{|l|}{ cstage } \\
\hline I & $30(88 \%)$ & $87(85 \%)$ & 0.668 \\
\hline II & $4(12 \%)$ & $15(15 \%)$ & \\
\hline CEA (ng/ml) & $2.2(1.6-3.1)$ & $2.0(1.3-3.0)$ & 0.367 \\
\hline CA19-9 (U/ml) & $9.5(6.0-15.3)$ & $8.0(6.0-14.0)$ & 0.202 \\
\hline
\end{tabular}

BMI, Body mass index; ASA, American Society of Anesthesiologists; CCI, Charlson comorbidity index. 
Table II. Operative outcomes. The range is expressed as median (interquartile range).

\begin{tabular}{|c|c|c|c|}
\hline & $\begin{array}{l}\text { Elderly group } \\
\quad(\mathrm{n}=34)\end{array}$ & $\begin{array}{l}\text { Non-elderly group } \\
\qquad(\mathrm{n}=102)\end{array}$ & $p$-Value \\
\hline Total blood loss (ml) & $86.5(48.5-143.3)$ & $70.5(30.0-161.3)$ & 0.509 \\
\hline Operative time (min) & $308(288.5-348.3)$ & $317(286.5-348)$ & 0.863 \\
\hline Conversion to open & $3(9 \%)$ & $1(1 \%)$ & 0.02 \\
\hline \multicolumn{4}{|l|}{ Lymph node dissection } \\
\hline $\mathrm{D} 1+$ & $19(56 \%)$ & $54(53 \%)$ & 0.766 \\
\hline D2 & $15(44 \%)$ & $48(47 \%)$ & \\
\hline $\begin{array}{l}\text { Number of retrieved } \\
\text { LNs }\end{array}$ & $34(22.0-47.0)$ & $31(21.0-42.3)$ & 0.641 \\
\hline $\begin{array}{l}\text { Number of } \\
\text { metastasized LNs }\end{array}$ & $0(0-0)$ & $0(0-0)$ & 0.656 \\
\hline Tumor size (mm) & $31(24.8-40.5)$ & $33(20.0-44.3)$ & 0.207 \\
\hline \multicolumn{4}{|l|}{$\begin{array}{l}\text { Depth of tumor } \\
\text { invasion }\end{array}$} \\
\hline $\mathrm{T} 1$ & $26(76 \%)$ & $77(75 \%)$ & 0.843 \\
\hline $\mathrm{T} 2$ & $3(9 \%)$ & $12(12 \%)$ & \\
\hline $\mathrm{T} 3$ & $3(9 \%)$ & $10(10 \%)$ & \\
\hline $\mathrm{T} 4$ & $2(6 \%)$ & $3(3 \%)$ & \\
\hline \multicolumn{4}{|l|}{ Lymph node metastasis } \\
\hline No & $27(79 \%)$ & $84(82 \%)$ & 0.412 \\
\hline N1 & $5(15 \%)$ & $12(12 \%)$ & \\
\hline N2 & 0 & $4(4 \%)$ & \\
\hline N3 & $2(6 \%)$ & $2(2 \%)$ & \\
\hline \multicolumn{4}{|c|}{ Histological differentiation } \\
\hline Well differentiated & $10(29 \%)$ & $27(26 \%)$ & 0.869 \\
\hline $\begin{array}{l}\text { Moderately } \\
\text { differentiated }\end{array}$ & $10(29 \%)$ & $33(32 \%)$ & \\
\hline Poorly differentiated & $10(29 \%)$ & $29(28 \%)$ & \\
\hline Signet ring-cell type & $4(12 \%)$ & $10(10 \%)$ & \\
\hline Other & 0 & $3(3 \%)$ & \\
\hline \multicolumn{4}{|l|}{ Pathological stage } \\
\hline $\mathrm{I}$ & $28(82 \%)$ & $85(83 \%)$ & 0.806 \\
\hline II & $3(9 \%)$ & $11(11 \%)$ & \\
\hline III & $3(9 \%)$ & $6(6 \%)$ & \\
\hline
\end{tabular}

Postoperative management. After the operation, patients were managed with standardized clinical protocols. We used epidural or intravenous anesthesia for postoperative pain control. An oral diet was started on postoperative day (POD) 4 . When the patients had no morbidities or other medical problems, they were discharged on POD12.

Follow-up. Adjuvant chemotherapy was recommended for patients with pathological stage II and III gastric cancer. The patients, who gave their informed consent, received S-1 adjuvant chemotherapy for 1 year. Patients were principally followed at 3-month intervals for the first 2 years, and at 6-month intervals for the next 3 years.

Statistical analysis. Data were analyzed using the JMP Pro $12^{\circledR}$ (SAS Institute Inc. Cary, NC, USA) software program. Patient characteristics were compared using the two-tailed Fisher's exact test or the chi-squared test as appropriate. Quantitative variables were compared using Student's $t$-test and expressed as the median. A two-way analysis of variance was used to compare the difference
Table III. Postoperative complications. The range is expressed as median (interquartile range).

\begin{tabular}{lccc}
\hline & $\begin{array}{c}\text { Elderly group } \\
(\mathrm{n}=34)\end{array}$ & $\begin{array}{c}\text { Non-elderly group } \\
(\mathrm{n}=102)\end{array}$ & $p$-Value \\
\hline Overall complication & $8(24 \%)$ & $16(16 \%)$ & 0.299 \\
Anastomotic leakage & $5(15 \%)$ & $7(7 \%)$ & 0.163 \\
Abscess & $3(9 \%)$ & $8(8 \%)$ & 0.856 \\
Anastomotic stenosis & $1(3 \%)$ & $2(2 \%)$ & 0.736 \\
Pancreatic fistula & $2(6 \%)$ & $5(5 \%)$ & 0.823 \\
Pneumonia & $2(6 \%)$ & $2(2 \%)$ & 0.241 \\
Delirium & 0 & $2(2 \%)$ & 0.411 \\
Postoperative stay & $11(11-16)$ & $12(11-16)$ & 0.118 \\
Mortality & 0 & 0 & 1 \\
\hline & & &
\end{tabular}

in body weight, the serum levels of albumin and hemoglobin, and PNI. The cumulative survival time was analyzed using the KaplanMeier method and log-rank test. $p$-Values of $<0.05$ were considered to indicate statistical significance. The mean follow-up period for all patients was 37 months.

\section{Results}

Patient characteristics. The characteristics of the patients are summarized in Table I. The median age of the patients in the elderly and the non-elderly groups was 78.5 and 67 years, respectively. The Charlson comorbidity index score, comorbidity rate, and percentage of patients with a past history of laparotomy were significantly higher in the elderly group. The percentages of patients with ASA scores $\geq 3$ and Glasgow Prognostic Score 1 and 2 were significantly higher in the elderly group. There were no significant differences between the two groups in sex, BMI, serum albumin and hemoglobin, PNI, respiratory functional parameters, clinical stage and tumor marker levels.

Intraoperative and pathological findings. There were no differences in total blood loss, operative time or the extent of lymph node dissection between the two groups. However, three patients were converted to open surgery in the elderly group due to severe adhesion in two cases and uncontrollable bleeding in one case. In contrast, one patient was converted to open surgery in the non-elderly group due to severe adhesion $(p=0.02)$. In all cases that were converted to laparotomy, the patients had a history of laparotomy, including partial gastrectomy, colectomy, cholecystectomy and appendectomy. Pathologically, the tumor site, macroscopic type, tumor size, depth of invasion, lymph node metastasis, histological type, and pathological stage did not differ between the two groups (Table II).

Postoperative course. The rates of postoperative complications, according to the Clavien-Dindo classifications, did not differ 
(\%) Body weight loss
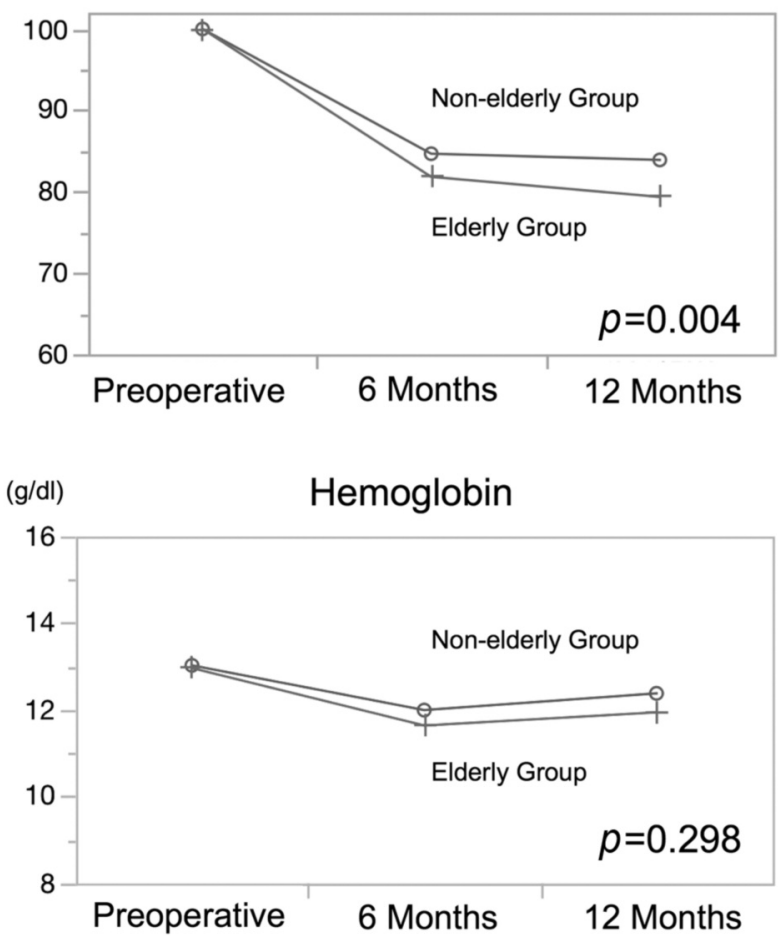

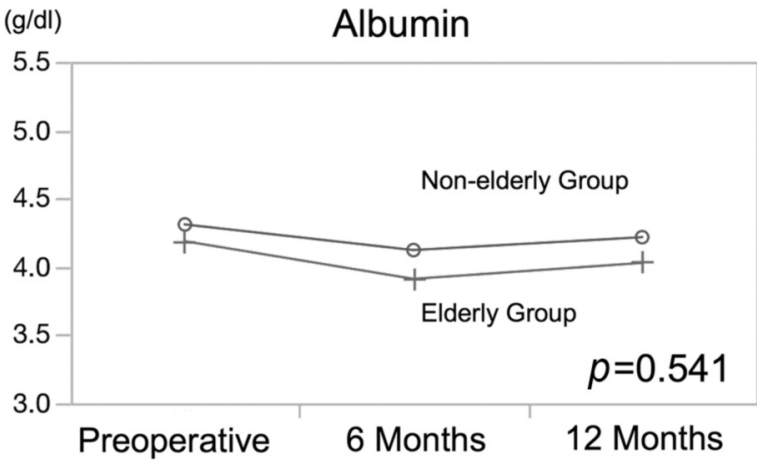

Prognostic nutritional index

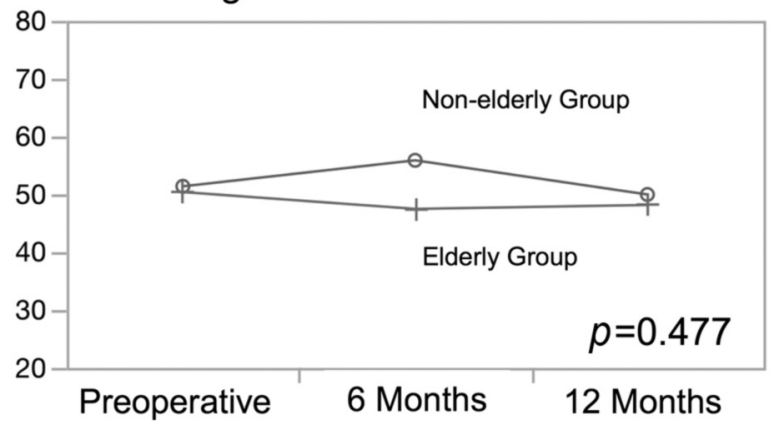

Figure 1. Comparisons of the postoperative nutritional status of the two groups. Body weight loss, albumin, hemoglobin, prognostic nutritional index. Body weight loss rate was significantly greater in the elderly group $(p=0.004)$. The serum levels of albumin and hemoglobin and PNI did not differ significantly between the two groups.

between the two groups (Table III). The rates of anastomotic leakage, abscess, anastomotic stenosis, pancreatic fistula, pneumonia, and delirium did not differ between the two groups. There were no differences in the postoperative hospital stay or mortality rate.

Long-term procedures. The rate of body weight loss in one year was significantly greater in the elderly group $(p=0.004)$. The serum levels of albumin and hemoglobin and PNI did not differ significantly between the two groups (Figure 1). A total of 11 patients $(32.4 \%)$ received nutritional support within one year after the operation in the elderly group, while 14 patients $(13.7 \%)$ received nutritional support in the non-elderly group $(p=0.015)$.

Long-term survival. The overall survival (OS) of the elderly group was significantly worse in comparison to the nonelderly group ( $p=0.003$ ). The 3 -year OS rates were $71.2 \%$ in the elderly group and $92.3 \%$ in the non-elderly group. In contrast, the disease-specific survival (DSS) did not differ between the two groups $(p=0.152)$. The 3 -year DSS rates were $83.7 \%$ in the elderly group and $94.5 \%$ in the nonelderly group (Figure 2). Adjuvant S-1 treatment was indicated for 5 patients in the elderly group, 2 of whom
(20\%) received it. In contrast, adjuvant S-1 treatment was indicated for 12 patients in the non-elderly group, 9 of whom $(75 \%)$ received it (Table IV).

A total of nine patients died in the elderly group: 4 patients died due to gastric cancer and 5 patients died of other diseases. A total of 7 patients died in the non-elderly group: 5 patients died due to gastric cancer and 2 patients died of other disease (Table V). There was a significant difference between the two groups in the number of patients who died of other diseases; however, no difference was observed in the number of patients who died of gastric cancer. Three patients in the elderly group and 1 patient in the non-elderly group died of cardiovascular and respiratory diseases.

Recurrence was observed in 4 patients (12\%) of the elderly group and 7 patients $(7 \%)$ of the non-elderly group $(p=0.364)$. In the elderly group, 2 patients were unable to receive chemotherapy due to a poor general condition, 1 patient received palliative radiation therapy and 1 patient received chemotherapy up to the second line (first-line, paclitaxel; second-line, irinotecan plus cisplatin). In contrast, 3 patients did not receive chemotherapy due to poor general conditions, 1 patient received chemotherapy up to the first line (S-1 plus oxaliplatin), and one patient received 
A

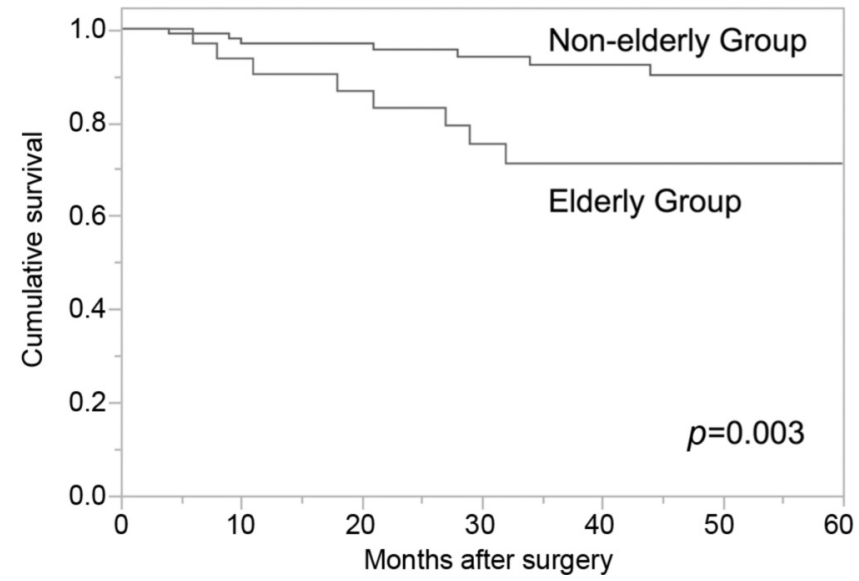

B

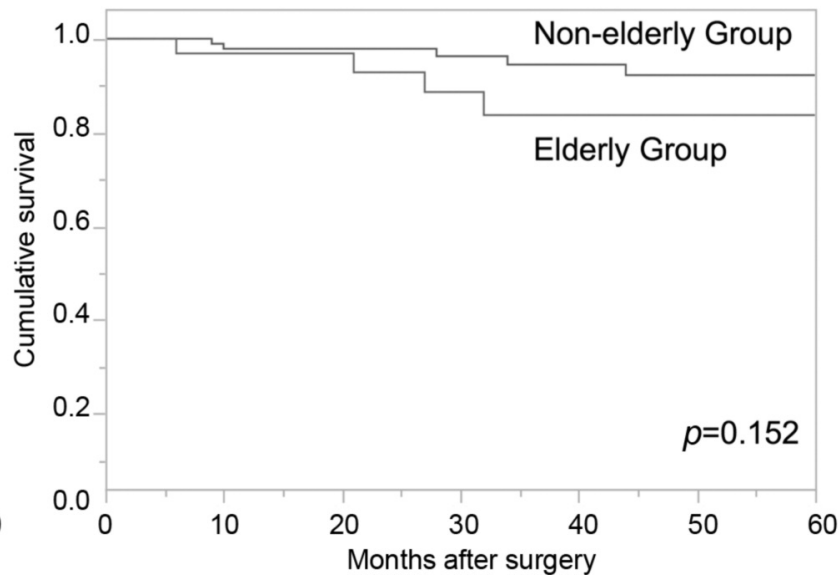

Figure 2. Kaplan-Meier plots of overall survival (A) and disease-specific survival (B). The overall survival (OS) of the elderly group was significantly worse in comparison to the non-elderly group $(p=0.003)$. The 3-year OS rates were $71.2 \%$ in the elderly group and $92.3 \%$ in the non-elderly group. The disease-specific survival (DSS) did not differ significantly between the two groups $(p=0.152)$. The 3-year DSS rates were $83.7 \%$ in the elderly group and $94.5 \%$ in the non-elderly group.

Table IV. Recurrence.

\begin{tabular}{|c|c|c|c|}
\hline & $\begin{array}{l}\text { Elderly group } \\
\qquad(\mathrm{n}=34)\end{array}$ & $\begin{array}{l}\text { Non-elderly group } \\
\qquad(\mathrm{n}=102)\end{array}$ & $p$-Value \\
\hline All & $4(12 \%)$ & $7(7 \%)$ & 0.364 \\
\hline Liver & 1 & 4 & \\
\hline Lung & 0 & 1 & \\
\hline Peritoneum & 3 & 1 & \\
\hline LN & 1 & 0 & \\
\hline Bone & 0 & 2 & \\
\hline Indication of adjuvant & TS-1 5 & 12 & 0.169 \\
\hline Received & 2 & 9 & \\
\hline Not received & 3 & 3 & \\
\hline
\end{tabular}

chemotherapy up to the third line (first-line, capecitabine plus cisplatin; second-line, paclitaxel plus ramucilumab; third-line, nivolumab). One patient in the non-elderly group is continuing to receive chemotherapy, and one patient with a poor general condition is being observed without chemotherapy.

\section{Discussion}

This study showed that the DSS of patients receiving LTG for gastric cancer did not differ between the elderly and nonelderly groups, although OS in the elderly group was poor due to death from other diseases. The surgical outcomes of laparoscopic gastrectomy for elderly patients with early gastric cancer have been reported in recent years $(2,16,17)$.
Table V. Cause of death.

\begin{tabular}{lccc}
\hline & $\begin{array}{c}\text { Elderly group } \\
(\mathrm{n}=34)\end{array}$ & $\begin{array}{c}\text { Non-elderly group } \\
(\mathrm{n}=102)\end{array}$ & $p$-Value \\
\hline All & $9(26 \%)$ & $7(7 \%)$ & 0.002 \\
Gastric cancer & $4(12 \%)$ & $5(5 \%)$ & 0.163 \\
$\begin{array}{l}\text { Postoperative } \\
\text { complication }\end{array}$ & 0 & 0 & 1 \\
$\begin{array}{l}\text { Other disease } \\
\quad \text { Cardiovascular }\end{array}$ & $5(15 \%)$ & $2(2 \%)$ & 0.004 \\
$\quad$ Respiratory & 1 & 1 & \\
$\quad$ Cardiopulmonary arrest & 1 & 0 & \\
$\quad$ Unknown & 1 & 1 & \\
\hline
\end{tabular}

However, most studies reported the short-term surgical outcomes of wholly laparoscopic gastrectomy or LDG, and there are a few reports on the outcomes of surgical treatment limited to LTG. In the present study, we examined the safety, feasibility and nutritional status of LTG for elderly patients in comparison to non-elderly patients.

Elderly patients originally have higher rates of various comorbidities in comparison to non-elderly patients. The previous studies on laparoscopic gastrectomy pointed out that preoperative comorbidities were important risk factors for postoperative complications $(2,16)$. Another study reports a higher incidence of anastomotic leakage after LTG in elderly patients, in comparison to non-elderly patients (18). In our study, there was no significant difference in complications; however, the incidence of preoperative 
comorbidities in elderly patients was significantly higher in comparison to non-elderly patients. However, the rate of anastomotic leakage was higher in the elderly group, and the rate of conversion to laparotomy was also significantly higher. Thus, careful attention to the surgical procedure is required for elderly patients. Since the percentage of patients with a history of abdominal surgeries increases with aging, it is necessary to sufficiently consider the indication of laparoscopic surgery and perform meticulous surgery in this population. In the present study, there were no significant differences in the other short-term outcomes; thus, our surgical procedures would be considered acceptable.

The only study limited to LTG showed no difference in OS or DSS (19). However, previous studies on the long-term outcomes of laparoscopic gastrectomy have reported that OS in an elderly group was poorer than that in non-elderly groups and that the DSS rates of the two groups were equivalent. In these studies, it was concluded that other causes of death affected OS in elderly patients $(4-6,17)$. This study was compatible to previous studies. The rate of patients who died of other diseases in the elderly group was significantly greater than that in the non-elderly group.

In the present study, the percentage of patients who died of gastric cancer was higher in the elderly group. The introduction of postoperative adjuvant chemotherapy was low and it was difficult to administer chemotherapy after recurrence due to a poor physical status in the elderly group. These reasons may affect the outcomes in elderly patients. This study also referred to the postoperative nutritional status of the elderly patients. Elderly patients physiologically lose their reserve capacity with age (20). Thus, we expected deterioration of the nutritional status following surgical invasion in the elderly group. However, other than body weight loss, there was no significant difference in the serum levels of albumin and hemoglobin, or in the PNI between the two groups. The body weight loss was significantly lower in the elderly group. The presence of higher weight loss, despite nutritional support, suggests a lower reserve capacity in elderly patients. High rates of comorbidity and a high Charlson comorbidity index may also have adverse effects on nutrition in the elderly. It is necessary to realize the physiological deterioration of the elderly and to implement an appropriate therapeutic strategy for each elderly gastric cancer patient.

The present study was associated with several limitations. This retrospective study had a small number of patients, the study was conducted in a single institute, and the follow-up period was relatively short. Thus, further prospective studies are necessary.

In conclusion, LTG is considered to be an acceptable procedure for elderly gastric cancer patients. A welldesigned, multi-institutional randomized controlled study that includes a large study population is necessary in order to confirm the validity of LTG in elderly patients.

\section{Compliance and Ethical Standards}

This study was conducted in accordance with the Declaration of Helsinki. The study was approved by the Yokohama City University Institutional Review Board (B200400019). Informed consent was obtained from all patients.

\section{Conflicts of Interest}

The Authors have no conflicts of interest directly relevant to the content of this article.

\section{Authors' Contributions}

All Authors made contributions to conception and design of the study. Date collection and analysis were performed by H.S., C.K., H.M., K.S., S.S., Y.T. and T.K. Interpretation of data was performed by H.S., C.K., N.Y., Y.R., H.A., I.E. and M.M. Drafting the article was performed by H.S. and C.K. This article was revised and approved by all Authors.

\section{References}

1 Kojima G, Iliffe S, Taniguchi Y, Shimada H, Rakugi $H$ and Walters K: Prevalence of frailty in japan: A systematic review and meta-analysis. J Epidemiol 27(8): 347-353, 2017. PMID: 28142044. DOI: $10.1016 /$ j.je.2016.09.008

2 Fujisaki M, Shinohara T, Hanyu N, Kawano S, Tanaka Y, Watanabe A and Yanaga K: Laparoscopic gastrectomy for gastric cancer in the elderly patients. Surg Endosc 30(4): 1380-1387, 2016. PMID: 26123337. DOI: 10.1007/s00464-015-4340-5

3 Konishi H, Ichikawa D, Itoh H, Fukuda K, Kakihara N, Takemura M, Okugawa K, Uchiyama K, Nakata M, Nishi H, Kosuga T, Komatsu S, Okamoto K and Otsuji E: Surgery for gastric cancer patients of age 85 and older: Multicenter survey. World J Gastroenterol 23(7): 1215-1223, 2017. PMID: 28275301. DOI: 10.3748/wjg.v23.i7.1215

4 Mohri Y, Yasuda H, Ohi M, Tanaka K, Saigusa S, Okigami M, Shimura T, Kobayashi M and Kusunoki M: Short- and long-term outcomes of laparoscopic gastrectomy in elderly patients with gastric cancer. Surg Endosc 29(6): 1627-1635, 2015. PMID: 25277478. DOI: $10.1007 / \mathrm{s} 00464-014-3856-4$

5 Shimada S, Sawada N, Oae S, Seki J, Takano Y, Ishiyama Y, Nakahara K, Maeda C, Hidaka E, Ishida F and Kudo SE: Safety and curability of laparoscopic gastrectomy in elderly patients with gastric cancer. Surg Endosc, 2018. PMID: 29602987. DOI: 10.1007/s00464-018-6177-1

6 Yasukawa D, Kadokawa Y, Kato S, Aisu Y and Hori T: Safety and feasibility of laparoscopic gastrectomy accompanied by $\mathrm{d} 1+$ lymph node dissection for early gastric cancer in elderly patients. Asian J Endosc Surg, 2018. PMID: 29577648. DOI: 10.1111/ ases. 12480

7 Kitano S, Iso Y, Moriyama M and Sugimachi K: Laparoscopyassisted billroth i gastrectomy. Surg Laparosc Endosc 4(2): 146148, 1994. PMID: 29577648.

8 Chen K, He Y, Cai JQ, Pan Y, Wu D, Chen DW, Yan JF, Maher $\mathrm{H}$ and Mou YP: Comparing the short-term outcomes of intracorporeal esophagojejunostomy with extracorporeal esophagojejunostomy after laparoscopic total gastrectomy for 
gastric cancer. BMC Surg 16: 13, 2016. PMID: 27000746. DOI: 10.1186/s12893-016-0130-9

9 Kunisaki C, Makino H, Kimura J, Takagawa R, Ota M, Kosaka $\mathrm{T}$, Akiyama $\mathrm{H}$ and Endo I: Application of reduced-port laparoscopic total gastrectomy in gastric cancer preserving the pancreas and spleen. Gastric Cancer 18(4): 868-875, 2015. PMID: 25398519. DOI: 10.1007/s10120-014-0441-4

10 Norero E, Munoz R, Ceroni M, Manzor M, Crovari F and Gabrielli M: Two-layer hand-sewn esophagojejunostomy in totally laparoscopic total gastrectomy for gastric cancer. J Gastric Cancer 17(3): 267-276, 2017. PMID: 28970957. DOI: 10.5230/jgc.2017.17.e26

11 Japanese Gastric Cancer Association: Japanese gastric cancer treatment guidelines 2010 (ver. 3). Gastric Cancer 14(2): 113123, 2011. PMID: 21573742. DOI: 10.1007/s 10120-011-0042-4

12 Chen K, Pan Y, Zhai ST, Yu WH, Pan JH, Zhu YP, Chen QL and Wang XF: Totally laparoscopic versus open total gastrectomy for gastric cancer: A case-matched study about short-term outcomes. Medicine (Baltimore) 96(38): e8061, 2017. PMID: 28930841. DOI: 10.1097/MD.0000000000008061

13 Huang CJ, Zhang RC, Mou YP, Zhou YC, Wang YY, Lu C and $\mathrm{Xu} \mathrm{XW:} \mathrm{Short} \mathrm{and} \mathrm{long-term} \mathrm{outcomes} \mathrm{of} \mathrm{laparoscopic} \mathrm{total}$ gastrectomy for gastric cancer: A single-center experience (retrospective cohort study). Int J Surg 51: 109-113, 2018. PMID: 29367040. DOI: 10.1016/j.ijsu.2018.01.027

14 Yamamoto M, Shimokawa M, Kawano H, Ohta M, Yoshida D, Minami K, Ikebe $\mathrm{M}$, Morita $\mathrm{M}$ and Toh $\mathrm{Y}$ : Benefits of laparoscopic surgery compared to open standard surgery for gastric carcinoma in elderly patients: Propensity score-matching analysis. Surg Endosc, 2018. PMID: 30030615. DOI: 10.1007/ s00464-018-6325-7
15 Onodera T, Goseki N and Kosaki G: [Prognostic nutritional index in gastrointestinal surgery of malnourished cancer patients]. Nihon Geka Gakkai Zasshi 85(9): 1001-1005, 1984. PMID: 6438478.

16 Kim SM, Youn HG, An JY, Choi YY, Noh SH, Oh SJ, Sohn TS and Kim S: Comparison of open and laparoscopic gastrectomy in elderly patients. J Gastrointest Surg 22(5): 785-791, 2018. PMID: 29549619. DOI: 10.1007/s11605-018-3741-x

17 Yoshida M, Koga S, Ishimaru K, Yamamoto Y, Matsuno Y, Akita S, Kuwabara J, Tanigawa K and Watanabe Y: Laparoscopyassisted distal gastrectomy is feasible also for elderly patients aged 80 years and over: Effectiveness and long-term prognosis. Surg Endosc 31(11): 4431-4437, 2017. PMID: 28378081. DOI: 10.1007/s00464-017-5493-1

18 Jung HS, Park YK, Ryu SY and Jeong O: Laparoscopic total gastrectomy in elderly patients $(>/=70$ years $)$ with gastric carcinoma: A retrospective study. J Gastric Cancer 15(3): 176182, 2015. PMID: 26468415. DOI: 10.5230/jgc.2015.15.3.176

19 Sheng S, Chen Y and Li C: Outcomes of laparoscopic total gastrectomy for elderly gastric cancer patients. J Cancer 9(23): 4398-4403, 2018. PMID: 30519345. DOI: 10.7150/jca.26858

20 Evers BM, Townsend CM, Jr. and Thompson JC: Organ physiology of aging. Surg Clin North Am 74(1): 23-39, 1994. PMID: 8108769.

Received June 5, 2020

Revised June 19, 2020

Accepted June 22, 2020 